\section{Seed Number and an Asymmetry Index of 'McIntosh' Apples}

\author{
Anne-Marie Brault and Domingos de Oliveira \\ Département des Sciences Biologiques, Université du Québec à Montréal, \\ Montréal, PQ H3C 3P8, Canada
}

Additional index words. aborted seeds, fertilized ovules, Malus domestica, pollination, seed shape, fruit shape

Abstract. In 'McIntosh' apples (Malus domestica Borkh.), the number of well-formed seeds and the number of fertilized ovules (well-formed plus aborted seeds) were correlated to yield an index of asymmetry for individual fruit. In spite of different flowering and pollination conditions in 1990 and 1991, the index of asymmetry decreased curvilinearly with increases in the number of well-formed seeds and of fertilized ovules in both years.
Québec apples are classified into two catof apples to these categories affects their commercial value. Apples exhibiting pronounced shape defects are not classified and most often destined for the juice market. Apple growers thus receive only a quarter of the price they would get for Fancy fruit. In this context, an assessment of certain factors influencing the shape and, consequently, the commercial quality of apples is relevant.

Apple flowers are hermaphroditic, but in most cultivars they are strongly self-incompatible (Free, 1960). Good harvests depend on cross-pollination by insects. Flowers of most apple cultivars contain 10 ovules. Thus, 10 pollen grains are necessary for the formation of 10 seeds. In 'McIntosh', pollination with highly compatible cultivars results in $2.6 \%$ to $14.6 \%$ of the fruit being lopsided, although there were always more than two seeds per apple (Latimer, 1931, 1933, 1937). Roberts (1946) found that irregularly shaped 'Wealthy' and 'McIntosh' apples were most frequent when apples contained fewer than two and three seeds, respectively. This irregularity has been attributed to inadequate pollination (Way, 1978). Latimer (1931) and Brittain (1933) noted that the distribution of seeds among the carpels also influenced the shape of apples and that the percentage of lopsided apples decreased with an increase in the number of seed-containing carpels. Heinicke (1917) reported that tissue development was reduced near empty carpels. The fact that fertilized ovules provide an important source of growth hormones, such as auxins (Luckwill, 1948, 1953, 1957), suggests a link between the distribution and the number of seeds among carpels, and the shape of the apple.

Received for publication 2 May 1994. Accepted for publication 12 Oct. 1994. We express our appreciation to the apple growers, Réjean and Céline Guertin, for access to their orchard; to Michèle Roy of Ministry of Agriculture and Fisheries of Québec for her collaboration; and to Michel Junger and David Hilbert for revision of this article. The cost of payment of page charges. Under postal regulations, this paper therefore must be hereby marked advertisement solely to indicate this fact. egories: Extra-fancy and Fancy. Assignment publishing this paper was defrayed in part by the
The objective of this study was to determine the influence of seed set on the radial symmetry of 'McIntosh' apples.

\section{Materials and Methods}

The apples used in this 2-year study (1990 and 1991) were sampled from trees of 'McIntosh'/M.26 planted in 1980 at St-Paul d'Abbotsford, Mont Yamaska, Québec. Ten beehives were introduced in the 10-ha orchard in the first year of the study, and 12 in the second. In 1990, flowering began 13 May and ended 26 May, while in 1991, flowering lasted from 13 to 18 May. Low temperature and high precipitation did not favor pollination in the first year. The percentage of flowers injured by low temperature during Winter 1990 was determined during bloom, by counting the number of open and killed flowers on a $42-\mathrm{cm}$ length of branch on each of 35 randomly chosen trees. The number of apples per tree was counted at harvest (15 Sept. 1990 and 4 Sept. 1991) on the same 12 trees. Random sampling as well as reasoned-choice sampling were used to collect apples in 1990. Reasoned- choice sampling allowed systematic selection of apples with either very low or very high asymmetry to ensure that both extremes of the distribution were represented. Only random sampling was carried out in the second year of the study. Sample size in 1990 was 146 apples, 96 from random sampling and 50 from reasoned-choice sampling, while 60 apples were used in 1991.

Each apple was sliced transversely, and the fertilized ovules were classified into two seed categories: well-formed and aborted. Full, fleshy seeds were defined as well-formed seeds. Seeds were aborted when the endosperm was resorbed, whether or not the tegument was shriveled. For each apple, the radius passing through each of the five vascular bundles between carpels was measured from the corresponding seed attachment site to the cuticle (Fig. 1). An index of asymmetry $\left(\mathrm{I}_{\mathrm{A}}\right)$ of shape of each apple was calculated using the equation $\mathrm{I}_{\mathrm{A}}=[(\mathrm{r} \max -\mathrm{r} \min ) / \mathrm{r} \max ] \times 100$, where $r$ max corresponds to the longest and $r$ min to the shortest radius measured for each apple.

With the exception of the number of apples per tree, all variables were tested for differences between the two years by analysis of variance. Because residuals were not normally distributed, the Mann-Whitney U test was applied to test for differences between the number of apples per tree in 1990 and 1991 (Scherrer, 1984). For both years of the study, regression analysis was performed to determine the relation between the $\mathrm{I}_{\mathrm{A}}$ and the number of well-formed seeds and the number of fertilized ovules.

\section{Results}

In 1990, low winter temperature killed $43 \%$ of flowers. The mean number of open flowers per unit length of branch $(42 \mathrm{~cm})$ in 1991 was about twice that in 1990 (Table 1). The number of apples per tree differed by $>100 \%$ between years (Table 1 ). Well-formed seeds per fruit on random samples differed

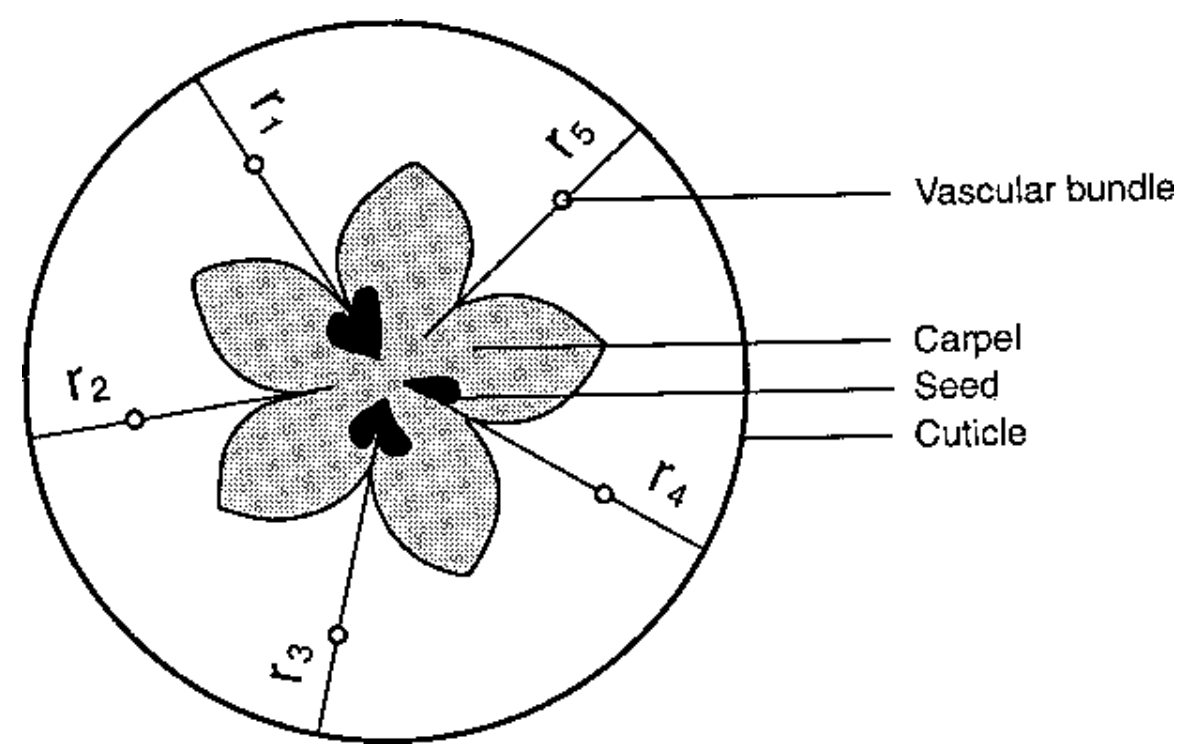

Fig. 1. Cross section of an apple showing the carpels, where $r_{1}, r_{2}, r_{3}, r_{4}$, and $r_{5}$ represent measured radia. 
significantly between years, while the mean number of aborted seeds and fertilized ovules and mean $\mathrm{I}_{\mathrm{A}}$ were similar for the two years of study (Table 2).

For the regression analyses, the $\mathrm{I}_{\mathrm{A}}$ was $\log$ transformed to correct for the heteroscedasticity and the departure from normality of residuals (Chartterjee and Price, 1977; Weisberg, 1980), but scatter plots of nontransformed data are presented (Figs. 2 and 3). All four regressions were significant and indicated that the $\mathrm{I}_{\mathrm{A}}$ was inversely related to the number of well-formed seeds (Fig. 2) and to the number of fertilized ovules (well-formed and aborted seeds combined) (Fig. 3).

\section{Discussion}

Despite the different flowering and pollination conditions in 1990 and 1991, the inverse relationships between the $\mathrm{I}_{\mathrm{A}}$ of apples and the number of well-formed seeds and the number of fertilized ovules were similar in both years. The number of fertilized ovules was similar in 1990 and 1991. However, there were significantly more well-formed seeds in 1991 than in 1990. The fact that the mean $I_{A}$ and the mean number of fertilized ovules did not differ between years suggests that wellformed and aborted seeds influence the shape of apples. These results support the findings of Luckwill (1948) on the developmental effects of auxin's diffusion from fertilized ovules. Thus, as expected, the lopsidedness of apples decreased with an increasing number of fertilized ovules. The sum of the number of aborted seeds plus the number of well-formed seeds in 1990 did not explain more variability in apple asymmetry than did well-formed seeds alone. Conversely, in 1991 the number of fertilized ovules was better related to fruit symmetry than was the number of well-formed seeds per fruit. In 1990, the low number of apples per tree may have masked the influence of aborted seeds on the development of apples. Hansen (1989) showed that the mean fresh weight of apples was inversely related to the number of apples per tree. We observed a similar relationship (data not shown). This compensation phenomenon could be the result of a lower competition for nutritional resources between the young fruits. Minimal competition could lead to less marked influence of the fertilized ovules on the $\mathrm{I}_{\mathrm{A}}$.

To our knowledge, this is the first study to quantify the relationship between symmetry and number of seeds or number of fertilized ovules per fruit. Previous reports simply indicated that there was a negative relationship between number of seeds per fruit and percentage of misshapen fruit (Latimer, 1937). In our study, 'McIntosh' apples containing at least six well-formed seeds or nine fertilized ovules were associated with an $\mathrm{I}_{\mathrm{A}}$ as low as $10 \%$. An $I_{A}>10 \%$ seems undesirable for this cultivar. Because the number of seeds in an apple reflects the degree of fertilization, apple growers aiming for high-quality production should try to achieve optimal pollination to increase the number of fertilized ovules, which is linked to the shape of apples.
Table 1. Mean numbers of flowers per 42-cm length of branch and of apples per tree, 1990 and 1991.

\begin{tabular}{|c|c|c|c|c|}
\hline \multirow[b]{2}{*}{ Year } & \multicolumn{2}{|c|}{$\begin{array}{l}\text { Flowers killed by low } \\
\text { winter temperature }\end{array}$} & \multirow[b]{2}{*}{ Total flowers } & \multirow[b]{2}{*}{ Apples/tree } \\
\hline & No. & $\%$ & & \\
\hline 1990 & 16.7 & 42.7 & $22.4 \mathrm{a}^{\mathrm{z}}$ & $113 a^{y}$ \\
\hline 1991 & --- & --- & $45.7 \mathrm{~b}$ & $259 \mathrm{~b}$ \\
\hline
\end{tabular}

${ }^{2}$ Mean separation by $\mathrm{F}$ test $(P \leq 0.0001)$.

y Mean separation by Mann-Whitney test $(P \leq 0.002)$.

Table 2. Mean numbers of well-formed and aborted seeds, of fertilized ovules, and mean value of the asymmetry index, 1990 and 1991.

\begin{tabular}{|c|c|c|c|c|}
\hline \multirow[b]{2}{*}{ Year } & \multicolumn{2}{|c|}{ Seeds (no.) } & \multirow{2}{*}{$\begin{array}{l}\text { Fertilized } \\
\text { ovules (no.) }\end{array}$} & \multirow{2}{*}{$\begin{array}{c}\text { Asymmetry } \\
\text { index }(\%)\end{array}$} \\
\hline & Well-formed & Aborted & & \\
\hline 1990 & $3.5 \mathrm{a}$ & $3.1 \mathrm{a}^{\mathrm{z}}$ & $6.7 \mathrm{a}$ & $15.7 \mathrm{a}$ \\
\hline 1991 & $4.6 \mathrm{~b}$ & $2.9 \mathrm{a}$ & $7.6 \mathrm{a}$ & $15.4 \mathrm{a}$ \\
\hline
\end{tabular}

${ }^{2}$ Mean separation in columns by analysis of variance $(P \leq 0.05)$.
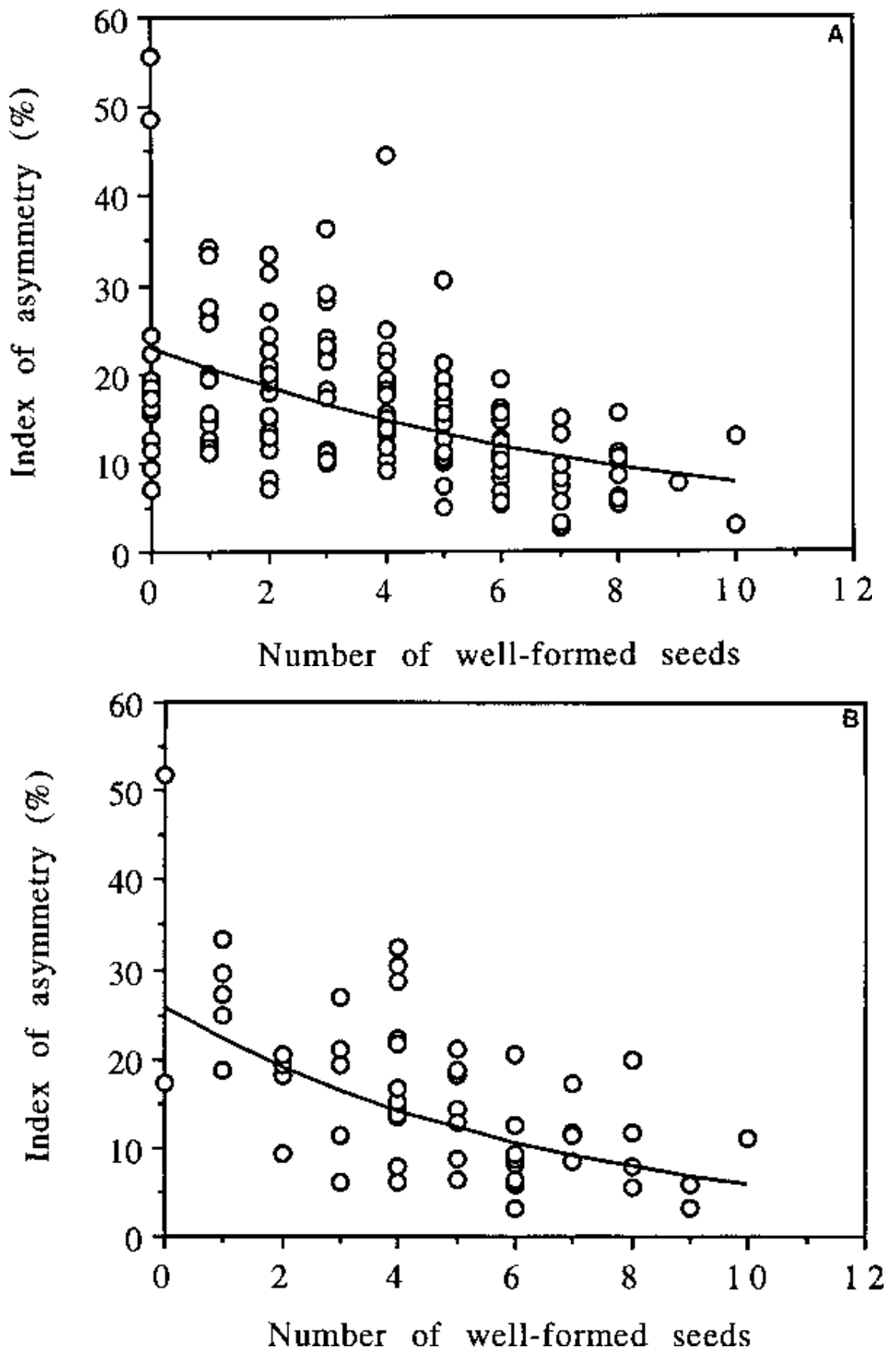

Fig. 2. Relationship between the number of well-formed seeds and the index of asymmetry; (A) 1990: $\log$ $\mathrm{y}=1.36-0.048 \mathrm{x}\left(r^{2}=0.32, \mathrm{n}=145, P<0.0001\right) ;($ B $) 1991: \log \mathrm{y}=1.41-0.065 \mathrm{x}\left(r^{2}=0.33, \mathrm{n}=60\right.$, $P<0.0001)$. 


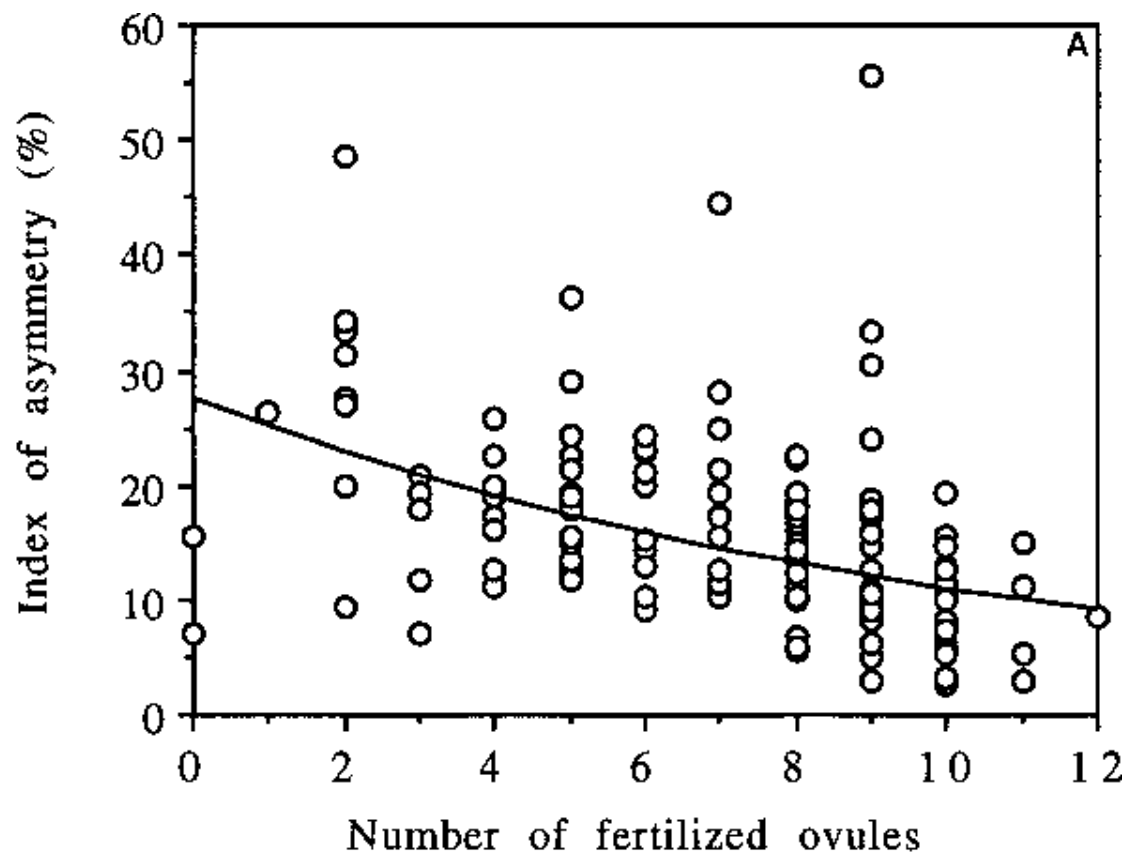

Literature Cited

Brittain, W.H. 1933. Apple pollination studies in the Annapolis Valley. Nova Scotia Can. Dept. Agr. Can. Bul. 162.

Chartterjee, S. and B. Price. 1977. Regression analysis by example. Wiley, Toronto.

Free, J.B. 1960. The pollination of fruit trees. Bee World 41:141-151.

Hansen, P. 1989. Source-sink relations in fruits v. pollination, fruit set, seed number, and fruit growth in apple cv. 'Summered'. Gartenbauwissenschaft 54:129-132.

Heinicke, A.J. 1917. Factors influencing the abscission of flowers and partially developed fruits of the apple (Pyrus malus L.). Cornell Univ. Agr. Expt. Sta. Bul. 393.

Latimer, L.P. 1931. Further observations on factors affecting fruit setting of the McIntosh apple in New Hampshire. Proc. Amer. Soc. Hort. Sci. 28:87-92.

Latimer, L.P. 1933. Pollination and fruit setting in the apple. New Hampshire Agr. Expt. Sta. Bul. 274.

Latimer, L.P. 1937. Self- and cross-pollination in the McIntosh apple and some of its hybrids. Proc. Amer. Soc. Hort. Sci. 34:19-21.

Luckwill, L.C. 1948. The hormone content of the seed in relation to endosperm development and fruit drop in apple. J. Hort. Sci. 24:32-44.

Luckwill,L.C. 1953. Studies of fruit development in relation to plant hormones. I. Hormone production by the developing apple seed in relation to fruit drop. J. Hort. Sci. 28:14-24.

Luckwill, L.C. 1957. Studies of fruit development in relation to plant hormones. IV. Acidic auxins and growth inhibitors in leaves and fruits of the apple. J. Hort. Sci. 32:18-33.

Roberts, R.H. 1946. Notes on apple set and growth, 1945. Proc. Amer. Soc. Hort. Sci. 48:59-62.

Scherrer, B. 1984. Biostatistique. G. Morin, Chicoutimi, Québec.

Way, R.D. 1978. Pollination and fruit set of fruit crops. New York Agr. Expt. Sta. Bul. 76.

Weisberg, S. 1980. Applied linear regression. Wiley, Toronto. 